\title{
KOMBINASI METODE ANP DAN TOPSIS DALAM MENENTUKAN PRIORITAS MEDIA PROMOSI PERGURUAN TINGGI (STUDI KASUS: STMIK AKAKOM YOGYAKARTA)
}

\author{
Sumiyatun ${ }^{1)}$, Retantyo Wardoyo ${ }^{2)}$ \\ ${ }^{1)}$ Teknik Informatika STMIK AKAKOM \\ Jln. Raya Janti 143, Karang Jambe, Yogyakarta \\ ${ }^{2)}$ Ilmu Komputer FMIPA UNIVERSITAS GADJAH MADA \\ Bulaksumur, Daerah Istimewa Yogyakarta \\ e-mail: sumiyatun@akakom.ac.id ${ }^{1)}$,rw@ugm.ac.id ${ }^{2)}$
}

\begin{abstract}
ABSTRAK
Perguruan tinggi merupakan sarana untuk mengembangkan ilmu. Setiap perguruan tinggi swasta akan menghadapi persaingan yang semakin ketat dan kompleks serta saling bersaing merebut calon mahasiswa. Salah satu pengaruh dari kesuksesan perolehan mahasiswa baru adalah pemilihan media promosi yang tepat. Penelitian ini bertujuan membangun suatu sistem pendukung keputusan yang dapat membantu bagian marketing di perguruan tinggi dalam menentukan prioritas media promosi.

Sistem pendukung keputusan yang dikembangkan dalam penelitian ini menggunakan metode ANP (Analytical Network Process) dan TOPSIS (Technique for Order Preference by Similarity to Ideal Solution). Metode ANP digunakan untuk menentukan bobot kriteria dengan memperhatikan pengaruh interdependence antar kriteria, sedangkan TOPSIS digunakan untuk menentukan peringkat alternatif media promosi.

Hasil dari penelitian ini adalah suatu sistem yang digunakan untuk menentukan prioritas media promosi berdasarkan kriteria - kriteria yang telah ditetapkan. Hasil pengujian menunjukkan bahwa sistem mampu memberikan urutan prioritas media promosi sebagai bahan pertimbangan dalam melakukan promosi perguruan tinggi.
\end{abstract}

Kata kunci : ANP, media promosi, perguruan tinggi, TOPSIS.

\section{ABSTRACT}

College as a higher education institution is one of the means to develop knowledge. Each of them will face a tight and complex rivalry as well as competing to attract potential students. One of the factors which influences potential students enrollment number is the proper choice of promotional medium. This research aims to develop a decision support system which can help the college's marketing department in determining the priority of media promotion.

The developing Decision support system in this study is using ANP (Analytical Network Proces) and TOPSIS (Technique for Order Preference by Similiarity to Ideal Solution). ANP method is used to determine the weights of criteria with notice to the influence of interdependence between the criteria while TOPSIS used to rank the alternative media campaign.

The results of this research is a system used to determine priorities media campaign based on criterias which has been set. The test results indicate that the system is able to giving priority sequece media campaign as consideration in promoting higher education. The results of this research is a system used to determine media campaign priorities based on criterias which has been set. The results test indicate that the system is able to give sequece media campaign priority as consideration in promoting colleges.

Keywords: ANP, Media promotion, college, TOPSIS.

\section{PENDAHULUAN}

$\mathrm{P}$ ersaingan yang semakin ketat menyebabkan perguruan tinggi harus menempatkan orientasi pada kepuasan pelanggan dalam hal ini adalah mahasiswa. Untuk dapat mencapai tujuan tersebut, maka perguruan tinggi harus berupaya menghasilkan dan menyampaikan apa yang diinginkan konsumen, memahami perilaku konsumen pada pasar sasarannya, karena kelangsungan hidup suatu usaha sangat tergantung pada perilaku konsumennya.

Menurut Widiyoko (2012) pemasaran perguruan tinggi sangat diperlukan. Posisi pemasaran perguruan tinggi memiliki posisi khusus dan otonomi strategi dalam rangka untuk memperoleh mahasiswa sesuai dengan target tiap tahun akademik. Akan tetapi tidak semua perguruan tinggi memiliki Unit Pemasaran, biasanya ada perguruan tinggi hanya memiliki Unit Humas atau Promosi. Unit tersebut menangani berbagai hal misalnya pemberitaan media, memberikan informasi kepada civitas akademik tentang kegiatan perguruan tinggi, serta melakukan promosi dengan media brosur, advertorial di media atau melakukan presentasi di tiap tiap sekolah SMA khususnya kelas XII.

Membuat keputusan menentukan media promosi dapat dikategorikan sebagai Multi Criteria Decision-Making (MCDM) problem. Pemilihan media promosi harus mempertimbangkan banyak faktor serta mengevaluasi pengaruh serta keterkaiatan antar faktor tersebut. Dalam hal ini, metode MCDM direkomendasikan karena dapat membantu dalam mendapatkan keputusan penting yang tidak dapat ditentukan secara langsung. 
Metode Analytical Network Process (ANP) dipilih oleh peneliti karena dalam menentukan prioritas media promosi diperlukan banyak kriteria dan pada penelitian ini akan diperhatikan juga hubungan antar kriteria, metode ANP menangani MCDM dan menurut Saaty (2004) ANP merupakan metode yang mampu merepresentasikan tingkat kepentingan berbagai pihak dengan mempertimbangkan saling keterkaitan antar kriteria dan sub kriteria yang ada. Selanjutnya metode ini dikombinasikan dengan Technique for Order Preference by Similarity to Ideal Solution (TOPSIS). Metode TOPSIS didasarkan pada konsep dimana alternatif terpilih yang terbaik tidak hanya memiliki jarak terpendek dari solusi ideal positif, namun juga memiliki jarak terpanjang dari solusi ideal negatif. Metode TOPSIS bisa membantu proses pengambilan keputusan yang optimal untuk menyelesaikan masalah keputusan secara praktis. Hal ini disebabkan konsepnya sederhana dan mudah dipahami, komputasinya efisien dan memiliki kemampuan untuk mengukur kinerja relatif dari alternatif-alternatif keputusan dalam bentuk matematis yang sederhana (Kusumadewi dkk, 2006). Pada penelitian ini metode ANP digunakan untuk menentukan bobot kritera yang mempertimbangkan hubungan interdependence antar kriteria. Selanjutnya hasil pembobotan akan digunakan dalam metode TOPSIS dalam menetukan jarak alternatif dengan solusi ideal positif dan negatif sehingga akan diperoleh urutan peringkat media promosi.

Permasalahan dalam penelitian ini adalah bagaimana membangun suatu sistem pendukung keputusan dengan metode ANP dan TOPSIS yang dapat membantu pengambil keputusan untuk menentukan prioritas media promosi yang akan digunakan oleh Perguruan Tinggi.

Tujuan yang akan dicapai dalam penelitian adalah membangun sebuah aplikasi sistem pendukung keputusan dengan menggunakan metode ANP dan TOPSIS yang dapat memberikan urutan peringkat dari beberapa alternatif media promosi.

\section{METODE}

\section{A. Sistem Pendukung Keputusan}

Dalam Turban dkk. (2005), Little mendefinisikan Sistem Pendukung Keputusan (SPK) atau Decision Support System (DSS) sebagai sekumpulan prosedur berbasis model untuk data pemrosesan dan penilaian guna membantu para manajer mengambil keputusan. Fungsi dari DSS adalah untuk membantu pengambilan keputusan dalam situasi yang semi terstruktur dan situasi tidak terstruktur, dimana tidak seorang pun tahu secara pasti bagaimana keputusan seharusnya dibuat. DSS dimaksudkan untuk membantu para pengambil keputusan untuk memperluas kapabilitas mereka, tetapi tidak untuk menggantikan penilaian mereka (Turban, 2005).

\section{B. Analytical Network Process (ANP)}

Metode Analytic Network Process (ANP) merupakan pengembangan metode Analytical Hierarchy Process (AHP). Pengambilan keputusan dalam AHP dilakukan dengan cara menyususun masalah - masalah dalam bentuk hirarki satu arah. Namun demikian banyak masalah - masalah dalam pengambilan keputusannya tidak selalu terstruktur dalam hirarki linear satu arah, tetapi dapat berupa jaringan yang komplek, dimana terjadi hubungan interdepndensi antar kriteria dalam proses pengambilan keputusan. Metode ANP dikembangkan untuk mengatasi hubungan interdependensi antar kriteria dalam pengambilan keputusan.

Menurut Shyur (2006) secara umum langkah utama dalam proses perhitungan bobot kriteria dengan ANP dibagi ke dalam tiga tahap.

1) Tahap 1

Tahap pertama yang dilakukan adalah melakukan evaluasi terhadap seluruh kriteria yang akan digunakan tanpa memperhatikan ketergantungan antar kriteria. Pada penelitian ini bobot prioritas dihitung dengan menggunakan metode logaritmic least square yaitu dengan cara:

a) Mengalikan nilai dari masing - masing baris dan menghitung akar pangkat $\mathrm{n}$.

$$
\bar{W}_{i}=\sqrt[n]{\prod_{j=1}^{n} a_{i j}}
$$

$\bar{W}_{i} \quad$ : bobot kriteria yang belum dinormalisasi

$a_{i j} \quad$ : penilaian kepentingan kriteria ke $-i$ dibandingkan dengan kriteria ke $-j$

$i \quad: 1$...n merupakan jumlah kriteria

b) Melakukan normalisasi terhadap akar pangkat untuk mendapatkan bobot yang sesuai.

$$
W_{i}=\frac{\bar{W}_{i}}{\sum_{i=1}^{n} \bar{W}_{i}}
$$

$W_{i} \quad$ : bobot kriteria ke $-i$ yang sudah dinormalisasi 


\section{2) Tahap 2}

Tahap selanjutnya adalah memeriksa pengaruh dari seluruh kriteria ke kriteria lainnya dengan menggunakan perbandingan berpasangan untuk mengetahui pengaruh interdependence yang ada antar kriteria. Sejumlah perbandingan berpasangan akan dilakukan untuk setiap kriteria. Perbandingan berpasangan ini dibutuhkan untuk mengidentifikasi seberapa besar nilai pengaruh relatif dari hubungan ketergantungan antar kriteria. Nilai nol diberikan pada kriteria yang tidak memiliki ketergantungan.

3) Tahap 3

Untuk memperoleh bobot prioritas kriteria dengan interdependence dilakukan dengan mensintesis hasil dari 2 tahap sebelumnya menggunakan Persamaan (3):

$$
W c_{i}=B \cdot W_{i}
$$

\section{Keterangan:}

$W c_{i} \quad$ : bobot prioritas kriteria dengan interdependence yang akan digunakan pada proses perhitungan TOPSIS

B $\quad$ : matriks dari pengaruh ketergantungan antar kriteria pada tahap 2

$W_{i} \quad$ : adalah bobot prioritas kriteria - kriteria pada tahap 1

\section{Technique for Order Preference by Similarity to Ideal Solution (TOPSIS)}

TOPSIS adalah salah satu metode pengambilan keputusan multi kriteria yang pertama kali diperkenalkan oleh Yonn dan Hwang pada tahun 1981. Ide dasar dari metode ini adalah bahwa alternatif yang dipilih memiliki jarak terdekat dengan solusi ideal positif dan yang terjauh dari solusi ideal negatif.

Secara umum, prosedur dari metode TOPSIS termodifikasi mengikuti langkah-langkah sebagai berikut:

1) Menentukan matriks keputusan yang ternormalisasi.

$$
r_{i j}=\frac{x_{i j}}{\sqrt{\sum_{i=1}^{m} x_{i j}^{2}}}
$$

Keterangan:

$r_{i j}:$ nilai data ternormalisasi berdasarkan tiap kriteria dari setiap alternatif

$x_{i j}$ : nilai data belum ternormalisasi berdasarkan tiap kriteria dari setiap alternatif.

$\mathrm{R}$ : Matriks keputusan ternormalisasi

i : $1,2, \ldots$ m merupakan jumlah alternatif (baris)

j $: 1,2, \ldots$ merupakan jumlah kriteria (kolom)

Berdasarkan Persamaan (4) akan diperoleh matriks ternormalisasi (R) yaitu

$$
R=\left[\begin{array}{cccc}
r_{11} & r_{12} & \ldots & r_{1 n} \\
r_{21} & r_{22} & \ldots & r_{2 n} \\
\vdots & \vdots & \ddots & \vdots \\
r_{m 1} & r_{m 2} & \cdots & r_{m n}
\end{array}\right]
$$

2) Menghitung solusi ideal positif dan solusi ideal negatif.

$$
\begin{aligned}
& S_{j}^{+}=\left\{r_{1}^{+}, \ldots, r_{n}^{+}\right\}=\left\{\begin{array}{l}
\operatorname{maks}_{i} r_{i j}, j \in B \\
\min _{i} r_{i j}, j \in C
\end{array}\right. \\
& S_{j}^{-}=\left\{r_{1}^{-}, \ldots, r_{n}^{-}\right\}=\left\{\begin{array}{l}
\operatorname{maks}_{i} r_{i j}, j \in C \\
\min _{i} r_{i j}, j \in B
\end{array}\right.
\end{aligned}
$$

Keterangan:

$r_{j}^{+}$: solusi ideal positif berdasarkan kriteria $\mathrm{ke}-\mathrm{j}$

$r_{j}^{-}$: solusi ideal negatif berdasarkan kriteria $\mathrm{ke}-\mathrm{j}$

$j \quad: 1,2, \ldots$ merupakan jumlah kriteria

$S_{j}^{+}$: solusi ideal positif terhadap kriteria $\mathrm{ke}-\mathrm{j}$

$S_{j}^{-}$: solusi ideal negatif terhadap kriteria $\mathrm{ke}-\mathrm{j}$

$B$ : himpunan kriteria yang bersifat benefit

$C$ : himpunan kriteria yang bersifat cost

3) Menghitung jarak antara nilai setiap alternatif dengan matriks solusi ideal positif dan matriks solusi ideal negatif.

$$
D_{i}^{+}=\sqrt{\sum_{j=1}^{n} W_{j}\left(r_{i j}-r_{j}^{+}\right)^{2}}
$$




$$
D_{i}^{-}=\sqrt{\sum_{j=1}^{n} W_{j}\left(r_{i j}-r_{j}^{-}\right)^{2}}
$$

Keterangan:

$i \quad: 1,2, \ldots$ m merupakan jumlah alternatif

$j \quad: 1,2, \ldots$ merupakan jumlah kriteria

$D_{i}^{+} \quad$ : jarak setiap alternatif dari solusi ideal positif $(\mathrm{Sj}+)$

$D_{\mathrm{i}}^{-}$: jarak setiap alternatif dari solusi ideal negatif $(\mathrm{Sj}-)$

$\mathrm{Sj}_{+}$: solusi ideal positif terhadap kriteria

$S_{j}^{-} \quad$ : solusi ideal negatif terhadap kriteria

$W_{j}$ : nilai bobot kriteria $\mathrm{ke}-\mathrm{j}$

$r_{\mathrm{i} j} \quad$ : nilai data ternormalisasi berdasarkan tiap kriteria dari setiap alternatif

4) Menghitung nilai closeness coefficient untuk setiap alternatif.

Tahap akhir dari TOPSIS adalah mencari nilai closeness coefficient yang merupakan nilai preferensi untuk setiap alternatif. Nilai closeness coefficient diperoleh dari nilai jarak setiap alternatif dari solusi ideal negatif $\left(D_{i}^{-}\right)$ dibagi dengan penjumlahan nilai jarak setiap alternatif dari solusi ideal negatif $\left(D_{i}^{-}\right)$dan solusi ideal positif $D_{i}^{+}$ seperti yang diberikan pada Persamaan (10) :

$$
C C_{i}=\frac{D_{i}^{-}}{D_{i}^{-}+D_{i}^{+}}
$$

Keterangan:

i $\quad: 1,2, \ldots$ merupakan jumlah alternatif media promosi

$C C \mathrm{i}:$ kedekatan tiap alternatif terhadap solusi ideal

$D_{i}^{+}$: jarak alternatif $A i$ dengan solusi ideal positif

$D_{\hat{\mathrm{i}}}^{-} \quad$ : jarak alternatif $A i$ dengan solusi ideal negatif

Selanjutnya nilai dari closeness coeffisient digunakan menentukan perangkingan dari alternatif, dimana alternatif dengan nilai $C C$ terbesar merupakan solusi yang dipilih.

\section{HASIL}

\section{Proses Pengambilan Keputusan}

Proses pengambilan keputusan diawali dengan menentukan kriteria - kriteria yang diperlukan didalam pemilihan media promosi di perguruan tinggi. Selanjutnya adalah menghitung bobot prioritas kriteria dengan mempertimbangkan pengaruh interdependence antar kriteria menggunakan metode ANP. Setelah memperoleh bobot prioritas kriteria dengan interdependence, selanjutnya adalah melakukan perankingan alternatif media promosi dengan menggunakan metode TOPSIS sehingga dapat diperoleh urutan prioritas media promosi. Tahapan proses yang dilakukan seperti terlihat pada Gambar 1.

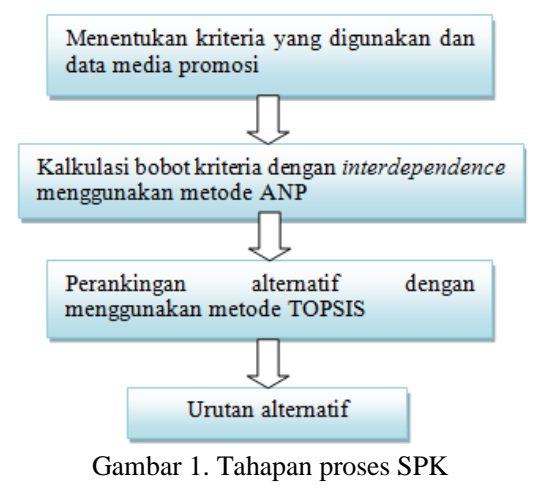

\section{E. Model ANP dan TOPSIS}

Tujuan yang dicapai adalah menentukan prioritas media promosi. Adapun kriteria yang digunakan adalah capaian target, tingkat pengaruh, biaya, jangkauan, dan kelengkapan informasi. Terlihat bahwa terdapat hubungan pengaruh interdependence antar kriteria. Hasil akhir yang diberikan oleh sistem adalah urutan prioritas media promosi dari alternatif media promosi yang ada. Gambar 2 menunjukkan pemodelan ANP dan TOPSIS yang dibuat. 


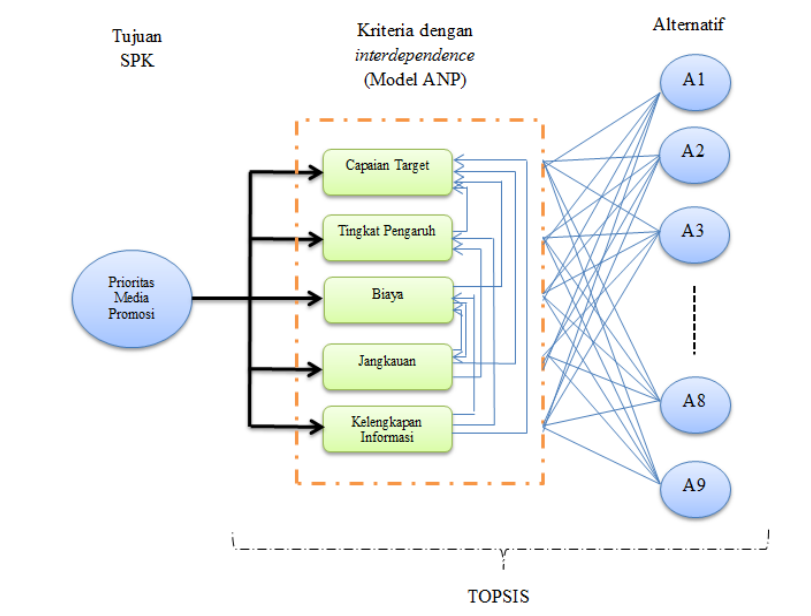

Gambar 2. Model ANP dan TOPSIS menentukan prioritas media promosi

\section{F. Pembobotan Kriteria dengan ANP}

Pembobotan kriteria dengan menggunakan ANP dlakukan dengan melalui tiga tahap. Adapun kriteria yang digunakan adalah capaian target (C1-CT), tingkat pengaruh (C2-TP), biaya (C3 - BI), jangkauan (C4-JK) dan kelengkapan informasi (C5-KI).

Tahap 1 - menentukan bobot kriteria tanpa interdependence

Pada tahap pertama ini dilakukan dengan perbandingan kepentingan antar kriteria.

TABEL I

BOBOT KRITERIA TANPA INTERDEPENDENCE

\begin{tabular}{lcccccc}
\hline \hline & C1-CT & C2-TP & C3-BI & C4-JK & C5-KI & Bobot \\
\hline C1-CT & 1 & 2 & 2 & 3 & 1 & 0,3014 \\
C2-TP & 0,5 & 1 & 1 & 2 & 0,5 & 0,1596 \\
C3-BI & 0,5 & 1 & 1 & 2 & 1 & 0,1834 \\
C4-JK & 0,3333 & 0,5 & 0,5 & 1 & 0,3 & 0,0877 \\
C5-KI & 1 & 2 & 0,3333 & 3,3333 & 1 & 0,2680 \\
\hline \hline
\end{tabular}

Tahap 2 - membuat matriks pengaruh interdependence antar kriteria

TABEL II

MATRIKS PENGARUH INTERDEPENDENCE

\begin{tabular}{lrrrrr}
\hline \hline & C1-CT & C2-TP & C3-BI & C4-JK & C5-KI \\
\hline C1-CT & 1 & 0 & 0 & 0 & 0 \\
C2-TP & 3 & 1 & 0 & 0 & 0 \\
C3-BI & 0,5 & 0 & 1 & 0,3 & 0 \\
C4-JK & 0,5 & 1 & 0,3 & 1 & 0 \\
C5-KI & 1 & 2 & 0,3 & 0 & 1 \\
\hline \hline
\end{tabular}

TABEL III

MATRIK PENGARUH INTERDEPENDENCE TERNORMALISASI

\begin{tabular}{lrrrrr}
\hline \hline & \multicolumn{1}{l}{ C1-CT } & \multicolumn{1}{c}{ C2-TP } & C3-BI & C4-JK & \multicolumn{1}{c}{ C5-KI } \\
\hline C1-CT & 0,1667 & 0,000 & 0,0000 & 0,0000 & 0,0000 \\
C2-TP & 0,5000 & 0,250 & 0,0000 & 0,0000 & 0,0000 \\
C3-BI & 0,0833 & 0,000 & 0,6250 & 0,2308 & 0,0000 \\
C4-JK & 0,0833 & 0,250 & 0,1875 & 0,7692 & 0,0000 \\
C5-KI & 0,1667 & 0,500 & 0,1875 & 0,0000 & 1,0000 \\
\hline \hline
\end{tabular}

Tahap 3 - menentukan bobot kriteria dengan interdependence

TABEL IV

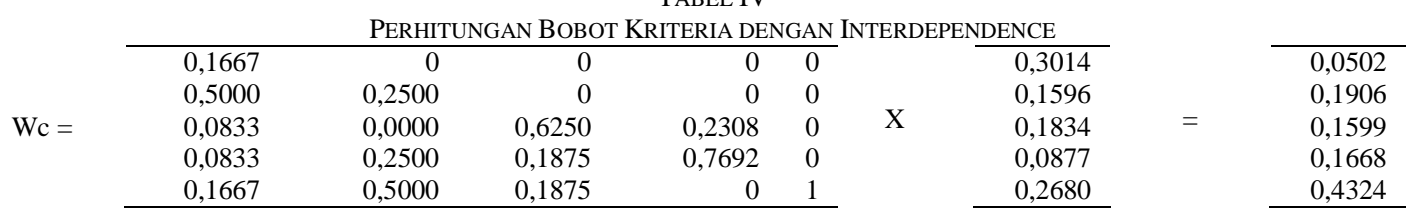

\section{G. Perangkingan media promosi dengan TOPSIS}

Alternatif yang digunakan dalam penelitian ini adalah Brosur (A1), Surat Kabar (A2), Baliho (A3), Spanduk (A4), Poster (A5), Round Tag (A6), Radio (A7), Televisi (A8), Web dan media sosial (A9). Perangkingan dengan metode TOPSIS dimulai dengan membuat matriks keputusan berdasarkan data yang ada. Selanjutnya matriks 
keputusan dibuat ternormalisasi. Pada penelitian ini matriks keputusan ternormalisasi berbobot tidak dikerjakan sehingga setelah matriks dinormalisasi selanjutnya adalah menentukan solusi ideal positif dan solusi ideal negatif. Langkah selanjutnya adalah menentukan jarak alternatif dengan solusi ideal positif dan negatif. Bobot yang diperoleh dari perhitungan dengan metode ANP digunakan pada tahap ini. Kemudian dilanjutkan dengan menghitung closeness coeffisient, dimana alternatif yang memiliki closeness coefficient terbesar merupakan prioritas tertinggi.

TABEL V

MATRIK KEPUTUSAN

\begin{tabular}{cccccc}
\multicolumn{7}{c}{ MATRIK KEPUTUSAN } \\
\hline \hline A1 & C1-CT & C2-TP & C3-BI & C4-JK & C5-KI \\
A2 & 5 & 5 & 27000000 & 4 & 5 \\
A3 & 10 & 4 & 17000000 & 3 & 3 \\
A4 & 3 & 3 & 13000000 & 3 & 3 \\
A5 & 8 & 3 & 11000000 & 3 & 3 \\
A6 & 3 & 3 & 12000000 & 3 & 3 \\
A7 & 7 & 4 & 17000000 & 3 & 4 \\
A8 & 8 & 5 & 20000000 & 4 & 4 \\
A9 & 25 & 5 & 5000000 & 5 & 5 \\
\hline \hline \multicolumn{7}{c}{} \\
\multicolumn{7}{c}{ TABEL VI } & & \\
\hline \hline A1 & 0,7101 & 0,4082 & 0,4900 & 0,3797 & 0,4437 \\
A2 & 0,1145 & 0,3266 & 0,3085 & 0,2847 & 0,2662 \\
A3 & 0,2291 & 0,3266 & 0,5354 & 0,2847 & 0,2662 \\
A4 & 0,0687 & 0,2449 & 0,2359 & 0,2847 & 0,2662 \\
A5 & 0,1832 & 0,2449 & 0,1996 & 0,2847 & 0,2662 \\
A6 & 0,0687 & 0,2449 & 0,2178 & 0,2847 & 0,2662 \\
A7 & 0,1603 & 0,3266 & 0,3085 & 0,2847 & 0,3549 \\
A8 & 0,1832 & 0,4082 & 0,3630 & 0,3797 & 0,3549 \\
A9 & 0,5726 & 0,4082 & 0,0907 & 0,4746 & 0,4437 \\
\hline \hline
\end{tabular}

TABEL VII

SOLUSI IDEAL POSISTIF DAN SOLUSI IDEAL NEGATIF

\begin{tabular}{cccccc}
\hline \hline & C1-CT & C2-TP & C3-BI & C4-JK & C5-KI \\
\hline$S^{+}$ & 0,7101 & 0,4082 & 0,0907 & 0,4746 & 0,4437 \\
$S^{-}$ & 0,0687 & 0,2449 & 0,5354 & 0,2847 & 0,2662 \\
\hline \hline
\end{tabular}

TABEL VIII

JARAK ALTERNATIF DENGAN SOLUSI IDEAL POSITIF DAN NEGATIF

\begin{tabular}{ccc}
\hline \hline Alternatif & $D^{+}$ & $D^{-}$ \\
\hline$A_{1}$ & 0,1643 & 0,2030 \\
$A_{2}$ & 0,2152 & 0,0980 \\
$A_{3}$ & 0,2533 & 0,0506 \\
$A_{4}$ & 0,2208 & 0,1198 \\
$A_{5}$ & 0,2014 & 0,1367 \\
$A_{6}$ & 0,2190 & 0,1270 \\
$A_{7}$ & 0,1829 & 0,1154 \\
$A_{8}$ & 0,1752 & 0,1241 \\
$A_{9}$ & 0,0308 & 0,2628 \\
\hline \hline
\end{tabular}

TABEL IX

Closeness CoefFicient

\begin{tabular}{cc}
\hline \hline Alternatif & closeness coefficient \\
\hline$A_{1}$ & 0,5526 \\
$A_{2}$ & 0,3130 \\
$A_{3}$ & 0,1666 \\
$A_{4}$ & 0,3517 \\
$A_{5}$ & 0,4044 \\
$A_{6}$ & 0,3671 \\
$A_{7}$ & 0,3870 \\
$A_{8}$ & 0,4146 \\
$A_{9}$ & 0,8951 \\
\hline \hline
\end{tabular}

IV. PEMBAHASAN

Pada penelitian ini metode ANP digunakan untuk menentukan bobot kriteria. Bobot tersebut kemudian digunakan dalam perhitungan menentukan jarak alternatif dengan solusi ideal positif dengan solusi ideal negatif pada metode TOPSIS untuk memperoleh urutan prioritas. Urutan prioritas didapatkan dari hasil perhitungan closeness coefficient mulai dari nilai terbesar. Dari hasil penelitian diperoleh hasil urutan prioritas media promosi prioritas pertama adalah web dan media soasial dengan nilai 0,8951. Prioritas kedua adalah brosur dengan nilai CC sebesar 0,5526. Peringkat ketiga televisi dengan nilai CC sebesar 0,4146. Peringkat keempat poster dengan nilai 
CC sebesar 0,4044. Peringkat kelima radio dengan nilai CC sebesar 0,3870. Peringkat keenam adalah round tag dengan nilai CC sebesar 0,3671. Peringkat ketujuh adalah spanduk dengan nilai CC sebesar 0,3517. Peringkat kedelapan adalah surat kabar dengan nilai CC sebesar 0,3130 dan peringkat terakhir adalah baliho dengan nilai CC sebaesar 0,1666. Selanjutnya hasil perangkingan ANP dan TOPSIS dibandingkan dengan perangkingan TOPSIS dengan menggunakan bobot kriteria tanpa interdependence (AHP) dan TOPSIS tanpa bobot menghasilkan urutan prioritas seperti pada Tabel X.

TABEL X

PERBANDINGAN PERANGKINGAN

\begin{tabular}{cllll}
\hline \hline Peringkat & TOPSIS tanpa bobot & TOPSIS dengan bobot AHP & TOPSIS dengan bobot ANP & Data Humas dan Admisi \\
\hline 1 & Web dan media sosial & Web dan media soasial & Web dan media soasial & Brosur \\
2 & Brosur & Brosur & Brosur & Web dan media soasial \\
3 & Poster & Poster & Televisi & Baliho \\
4 & Televisi & Televisi & Poster & Poster \\
5 & Round tag & Radio & Televisi \\
6 & Radio & Round tag & Radio \\
7 & Spanduk & Spanduk tag & Surat Kabar \\
8 & Surat kabar & Surat kabar & Surat kabar & Spanduk \\
9 & Baliho & Baliho & Baliho & Round Tag \\
\hline \hline
\end{tabular}

\section{SIMPULAN DAN SARAN}

Kesimpulan yang dapat diambil dari penelitaian ini adalah

1) Sistem yang dibangun mampu menampilkan urutan prioritas media promosi sehingga dapat digunakan oleh bagian humas dan admisi dalam mengambil keputusan dalam menentukan media promosi perguruan tinggi.

2) Metode ANP dan TOPSIS menghasilkan urutan prioritas yang berbeda dengan prioritas yang ditetapkan oleh bagian humas dan admisi, hal ini disebabkan karena perangkingan yang dilakukan bagian humas dan admisi tidak mempertimbangkan bobot kriteria dan pengaruh interdependence antar kriteria.

3) Web dan media sosial sebagai prioritas pertama media promosi yang dihasilkan dari penggunaan metode ANP dan TOPSIS sama dengan perangkingan yang menggunakan metode AHP dan TOPSIS maupun dengan menggunakan metode TOPSIS tanpa bobot.

Saran yang dapat diambil dari penelitian ini adalah

1) Penelitian ini hanya menggunakan kriteria dengan satuan nilai yang sama, untuk penelitian lebih lanjut dapat dikembangkan untuk kriteria dengan satuan nilai yang berbeda.

2) Untuk penelitian selanjutnya disarankan menggunakan perhitungan bobot kriteria dengan menggunakan langkah pendekatan ANP dan perangkingan dengan alternatif menggunakan pendekatan lain kemudian hasilnya dapat diperbandingkan dengan penelitian ini.

\section{REFERENSI}

[1] Kusumadewi, S., Hartati, S., Harjoko, A., dan Wardoyo, R., 2006, Fuzzy Multi Atribut Decision Making (Fuzzy MADM), Graha Ilmu, Yogyakarta.

[2] Saaty, T.L., 1996, Decisionmaking with dependence and feedback: the analyticnetwork process, RWS Publications, Pittsburgh.

[3] Saaty, T.L., 2001, Decision Making with Dependence and Feedback: The Analytic Network Process, Edisi 2, RWS Publications, Pittsburgh.

[4] Saaty, T.L., 2004, Fundamentals of the analytic network process dependence and feedback in decision-making with a single Network. RWS Publications, Pittsburgh

[5] Saaty, T.L. dan Vargas, L.G., 1984, Comparison of Eigenvalue, Logarithmic Least Squares and Least Squares Methods in Estimating Ratio, Mathematical Modelling Journal, 5, pp.309-324.

[6] Shyur, H.J., 2006, COTS evaluation using modified TOPSIS and ANP, Applied Mathematics and Computation. No.177, Hal. 251 - 259

[7] Turban, E., Aronson, J. E., dan Liang, T.P., 2005, Decision Support Sistems and Intelligent Sistems, Edisi Bahasa Indonesia jilid 1, diterjemahkan oleh: Dwi Prabantini, Penerbit ANDI, Yogyakarta.

[8] Widiyoko S., 2012, Strategi Marketing Perguruan Tinggi, http://www.kompasiana.com/setiawan_wd/strategi-marketing-perguruantinggi_550e68b2a33311a32dba8275, diakses tanggal 27 Oktober 2015 